\title{
Myocyte enhancer factor 2D provides a cross-talk between chronic inflammation and lung cancer
}

\author{
Hai-xing Zhu ${ }^{1,3 \dagger}$, Lin Shi ${ }^{2 \dagger}$, Yong Zhang ${ }^{2,3}$, Yi-chun Zhu², Chun-xue Bai ${ }^{2,3}$, Xiang-dong Wang ${ }^{4,5}$ \\ and Jie-bai Zhou ${ }^{2,3^{*}}$
}

\begin{abstract}
Background: Lung cancer is the leading cause of cancer-related morbidity and mortality worldwide. Patients with chronic respiratory diseases, such as chronic obstructive pulmonary disease (COPD), are exposed to a higher risk of developing lung cancer. Chronic inflammation may play an important role in the lung carcinogenesis among those patients. The present study aimed at identifying candidate biomarker predicting lung cancer risk among patients with chronic respiratory diseases.

Methods: We applied clinical bioinformatics tools to analyze different gene profile datasets with a special focus on screening the potential biomarker during chronic inflammation-lung cancer transition. Then we adopted an in vitro model based on LPS-challenged A549 cells to validate the biomarker through RNA-sequencing, quantitative real time polymerase chain reaction, and western blot analysis.

Results: Bioinformatics analyses of the 16 enrolled GSE datasets from Gene Expression Omnibus online database showed myocyte enhancer factor 2D (MEF2D) level significantly increased in COPD patients coexisting non-small-cell lung carcinoma (NSCLC). Inflammation challenge increased MEF2D expression in NSCLC cell line A549, associated with the severity of inflammation. Extracellular signal-regulated protein kinase inhibition could reverse the up-regulation of MEF2D in inflammation-activated A549. MEF2D played a critical role in NSCLC cell bio-behaviors, including proliferation, differentiation, and movement.

Conclusions: Inflammatory conditions led to increased MEF2D expression, which might further contribute to the development of lung cancer through influencing cancer microenvironment and cell bio-behaviors. MEF2D might be a potential biomarker during chronic inflammation-lung cancer transition, predicting the risk of lung cancer among patients with chronic respiratory diseases.
\end{abstract}

Keywords: Clinical bioinformatics, Inflammation, Lung cancer, Biomarker, Myocyte enhancer factor 2D

\section{Background}

Lung cancer is the most prevalent malignant tumor and the leading cause of cancer-related morbidity and mortality worldwide [1], mainly cataloged into non-small-cell lung carcinoma (NSCLC), large-cell carcinoma (LCC), and small-cell lung carcinoma (SCLC). Patients with

\footnotetext{
*Correspondence: zhou.jiebai@zs-hospital.sh.cn

${ }^{\dagger}$ Hai-xing Zhu and Lin Shi contributed equally to this work

${ }^{2}$ Department of Pulmonary Medicine, Zhongshan Hospital, Fudan

University, 180 Fenglin Road, Shanghai 200032, China

Full list of author information is available at the end of the article
}

chronic respiratory diseases are predisposed to higher incidence of lung cancer [2-7]. Chronic obstructive pulmonary disease (COPD), a chronic inflammatory lung disease, is closely related to susceptibility to lung cancer and stands as the most important risk factor of lung cancer among smokers [8]. Patients with moderate-to-severe COPD have a fivefold higher risk of developing lung cancer than smokers without the disease [9]. Chronic inflammation associated with COPD seems to play a critical role in cancer evolution. However, there is limited knowledge how the transition from chronic inflammation to 
lung cancer is triggered. The emergency of genomics and clinical bioinformatics allows defining gene alterations during the process of carcinogenesis to further understand the relationship between chronic inflammation and the onset of lung cancer.

The myocyte enhancer factor 2 (MEF2) family of human transcription factors, consisting of four subtypes, MEF2-A, -B, - C and -D, have a diversity of functions in different tissues and have been implicated in numerous diseases. MEF2s play an important role in the activation of the genetic processes that control cell differentiation, proliferation, and apoptosis in a wide range of cell types [10]. It has been reported that MEF2 is correlated with lower physical activity in COPD patients [11]. Altered MEF2 activity has been revealed as driver of cancer development, including both hematological cancers and solid tumor. Recent study found that MEF2 genes might act as oncogenes in NSCLC [12].

The present study is aimed to figure out candidate "communicator" between chronic inflammation and lung cancer and determine the potential regulatory mechanism. We highlight studies exploring the link between inflammation and cancer and discuss emerging biomarker for predicting risk of lung cancer among patients with chronic respiratory diseases.

\section{Methods}

\section{Bioinformatics tools}

We used "lung cancer" as the search keyword and "human" as organism to search for GSE datasets in Gene Expression Omnibus (GEO) online database. GSE datasets containing comparative gene expression profiling between lung cancer and non-cancer tissues, pathological definitions, and information of data normalizing methods were enrolled in the present study. Gene expression profiling data of each dataset were restored to original data, re-normalized with reference genes, and transformed to the ratio of expression data, and then integrated into one dataset. Genes with twofolds and more than twofolds up or down change in lung cancer subtypes were thought to be significantly differential genes, compared with noncancer tissues. All the differential genes were used in further bioinformatics analysis.

\section{Cell culture}

Human NSCLC cell line A549 cells, human bronchial epithelial cell line HBE cells, and human normal bronchial epithelial cell line BEAS-2B cells were obtained from Shanghai Institute for Biological Science. Cells were cultured in DMEM (high glucose, Hyclone, Logan, UT, USA), supplemented with 10\% FBS (Hyclone, Logan, UT, USA), 100 U/ $\mathrm{ml}$ penicillin, and $100 \mu \mathrm{g} / \mathrm{ml}$ streptomycin at $37{ }^{\circ} \mathrm{C}$ in a $5 \%$ $\mathrm{CO}_{2}, 95 \%$ air environment in humidified incubators.

\section{Ion Torrent-based RNA-sequencing}

RNA extraction was performed using the TRIZOL ${ }^{\mathrm{TM}} \mathrm{LS}$ reagent (Invitrogen, Carlsbad, CA, USA). rRNA depletion was performed using the RiboMinus ${ }^{\mathrm{TM}}$ Eukaryote System v2 $\left(\right.$ Ambion $\left.^{\circledR}\right)$ following standard protocols. First, total RNA was hybridized with biotinylated RiboMinus ${ }^{\mathrm{TM}}$ Eukaryote Probe Mix v2. Next, the rRNA-probe complexes were removed from the total RNA by captured with streptavidin-conjugated RiboMinus ${ }^{\mathrm{TM}}$ Magnetic Beads. The resulting rRNA-depleted RNA was concentrated and purified with Nucleic Acid Binding Beads. The cDNA libraries were barcoded using the ion total RNASeq Kit v2 (Ambion $\left.{ }^{\circledR}\right)$ following standard protocols. RNA sequencing was performed on the Ion Proton ${ }^{\text {TM }}$ System (Life Technologies, Carlsbad, CA, USA). Data analysis was performed using Torrent Suite ${ }^{\mathrm{TM}}$ Software 4.0 (Ion Torrent). Genes with twofolds and more than twofolds up or down change in LPS-stimulated A549 cells were thought to be significant, compared with the control group.

\section{Quantitative real time polymerase chain reaction (qRT-PCR) analysis}

RNA extraction was performed using the TRIZOL ${ }^{\mathrm{TM}} \mathrm{LS}$ reagent (Invitrogen, Carlsbad, CA, USA). cDNA was prepared using PrimeScript ${ }^{\circledR}$ RT reagent Kit (Takara, Shiga, Japan) following standard protocols. qRT-PCR was performed using SYBR ${ }^{\circledR}$ Premix Ex Taq ${ }^{\text {TM }}$ (Takara, Shiga, Japan) on the ABI 7000 PCR instrument (Eppendorf, Hamburg, Germany) with the following two-stage program parameters: $1 \mathrm{~min}$ at $95^{\circ} \mathrm{C}$ and then 40 cycles of $5 \mathrm{~s}$ at $95^{\circ} \mathrm{C}$ and $30 \mathrm{~s}$ at $60^{\circ} \mathrm{C}$. All samples were run in triplicate, and each group had six wells. Results were shown as relative target mRNA levels. The sequences of the primers used for this analysis are as follows:

MEF2A Forward, 5'-CCGACTGCCTACAACACTGA-3', MEF2A Reverse, 5'-GATAACTGCCCTCCAGCAAC-3'; MEF2B Forward, 5'-AAGTTCGGGCTGATGAAGAA-3', MEF2B Reverse, 5'-CATACTGGAAGAGGCGGTTG-3'; MEF2C Forward, 5'-CTGGCAACAGCAACACCTAC-3', MEF2C Reverse, 5'-GAAGGCAGGGAGAGATTTG-3'; MEF2D Forward, 5'-CACCTGACAATCACCCACAC-3', MEF2D Reverse, 5'-AGCATCACCATACAGCACGA-3'; GAPDH Forward, 5'-CCACCCATGGCAAATTCCATG GCA-3',

GAPDH Reverse, 5'-TCTACACGGCAGGTCAGGTC CACC-3'.

\section{Western bolt analysis}

Intracellular protein was extracted by radio immunoprecipitation assay lysis buffer. Protein samples $(50 \mu \mathrm{g})$ were mixed with an equal volume of $5 \times$ sodium dodecyl sulfate buffer, boiled for $5 \mathrm{~min}$, and then separated through $10 \%$ sodium dodecyl sulfate-polyacrylamide gel 
electrophoresis gels. Proteins were transferred to polyvinylidene fluoride membranes by electrophoretic transfer after electrophoresis. Membranes were blocked in 5\% dry milk for $2 \mathrm{~h}$, rinsed, and incubated with primary antibodies (diluted at their instructions) in TBS thrice at $4{ }^{\circ} \mathrm{C}$ overnight. Primary antibody was then removed by washing in TBS and labeled by incubating with $0.1 \mathrm{mg} / \mathrm{ml}$ peroxidase-labeled secondary antibodies (against mouse and rabbit) for $2 \mathrm{~h}$. Following three washes in TBS, bands were visualized by ECL (Tanon, Shanghai, China) and exposed to X-ray film. The band densities were quantified with Image J. The results were presented as ratio of band density to total actin.

\section{Small interfering RNA (siRNA) transfection}

Three different sequences targeting MEF2D (Additional file 1: Table S1) were designed and provided by GenePharma (Shanghai, China). siRNA transfection was performed according to the manufacturer's protocol. Briefly, $1 \mu \mathrm{l}$ Lipofectamine 2000 and 50 pmol each siRNA were mixed. Cells were then transfected with Lipofectamine/ siRNA complexes and incubated at $37^{\circ} \mathrm{C}$ for $24 \mathrm{~h}$. Transfection efficiency was evaluated by qRT-PCR and Western Blot analysis. Clones with optimized transfection were selected for stable transfection of MEF2D and used in the experiments.

\section{Alive measurement of cell bio-behaviors}

The cell bio-behaviors including total cell number, cell differentiation, and cell movement were dynamically measured through a Cell-IQ platform (Chip-Man Technologies, Tampere, Finland), equipped with a phase-contrast microscope (Nikon CFI Achromat phase contrast objective with $\times 10$ magnification) and a camera (Nikon, Fukasawa, Japan). The equipment was controlled by Imagen software (Chip-Man Technologies). Images were captured every $5 \mathrm{~min}$ for $72 \mathrm{~h}$. Analysis was carried out with a freely distributed Image software (Cell-IQ Imagen v2.9.5c; McMaster Biophotonics Facility, Hamilton, ON, Canada), using the Manual Tracking plug-in created by Fabrice Cordelieres (Institut Curie, Orsay, France). Cell-IQ system can monitor and record time-lapse data through machine vision technology, as well as analyze and quantify cell functions and morphological parameters. Here, we use this system to calculate cell numbers of each stage (dividing/stable stage) during proliferation, discriminate cell stage, and quantify the movement of each individual cell. Each group contained 6-12 replicate image sites.

\section{Cell migration assay}

In the Transwell assay (Corning Inc., Corning, NY, USA), cells were seeded in the upper chamber at the concentration of $5 \times 10^{5} / \mathrm{ml}$ in serum-free medium, while medium containing $10 \%$ FBS was added to the lower chamber. Cells migrated through the permeable membrane at $48 \mathrm{~h}$ were fixed and stained with Giemsa, and then counted under microscope.

\section{Cell proliferation assay}

In the cell proliferation assay, cells were seeded in 96-well plates at the concentration of $1 \times 10^{4} /$ well and incubated with AR $(40 \mathrm{ng} / \mathrm{ml})$ for 24,48 or $72 \mathrm{~h}$ at $37^{\circ} \mathrm{C}$ with $5 \%$ $\mathrm{CO}_{2}$, after which $10 \mu \mathrm{l}$ of the Cell Counting Kit-8 solution (Dojindo, Japan) was added to the medium. After 2-h incubation, the amount of orange formazan dye generated was determined by measuring the absorbance at $450 \mathrm{~nm}$ under microplate reader (Thermo Scientific, Carlsbad, CA, USA).

\section{Statistical analysis}

All values were expressed as mean \pm SEM. Statistical analysis was performed using SPSS software (SPSS 20.0; SPSS Inc; Chicago, IL, USA). Values between lung cancer subtypes were analyzed with Students's $t$ test and MannWhitney $U$ test. Data were evaluated using ANOVA with LSD test for multiple comparisons and Students's $t$ test between two groups. $p<0.05$ was considered as statistical significant.

\section{Results}

\section{Elevated MEF2D level in COPD patients with NSCLC}

16 GSE datasets containing comparative gene expression profiles of lung cancer and non-cancer tissues, pathological definitions, and information of data normalizing methods were enrolled in the present study through clinical bioinformatics tools. There were totally 677 NSCLC, 9 LCC, 56 SCLC cases, and 590 non-cancer cases. In patients with NSCLC, the expressions of MEF2A and MEF2D were significantly higher, compared with noncancer tissues (Fig. 1a, p $<0.01$ and 0.001, respectively). In patients with LCC or SCLC, the expressions of MEF2A were significantly lower, compared with non-cancer tissues (Fig. 1b, c, p $<0.01$, and 0.001 , respectively). The MEF2D levels were also decreased in patients with LCC or SCLC as compared with non-cancer tissues (Fig. 1b, c). Further data mining demonstrated significantly higher MEF2D level in COPD patients with NSCLC than that in smokers, patients with COPD and no NSCLC, or patients with NSCLC and no COPD, compared with healthy nonsmokers (Fig. 1d, p < 0.001).

\section{Increased MEF2D expression inflammation-activated NSCLC cell line}

We carried out Ion Torrent-based RNA-sequencing in a model of LPS-challenged NSCLC cell line A549. A549 


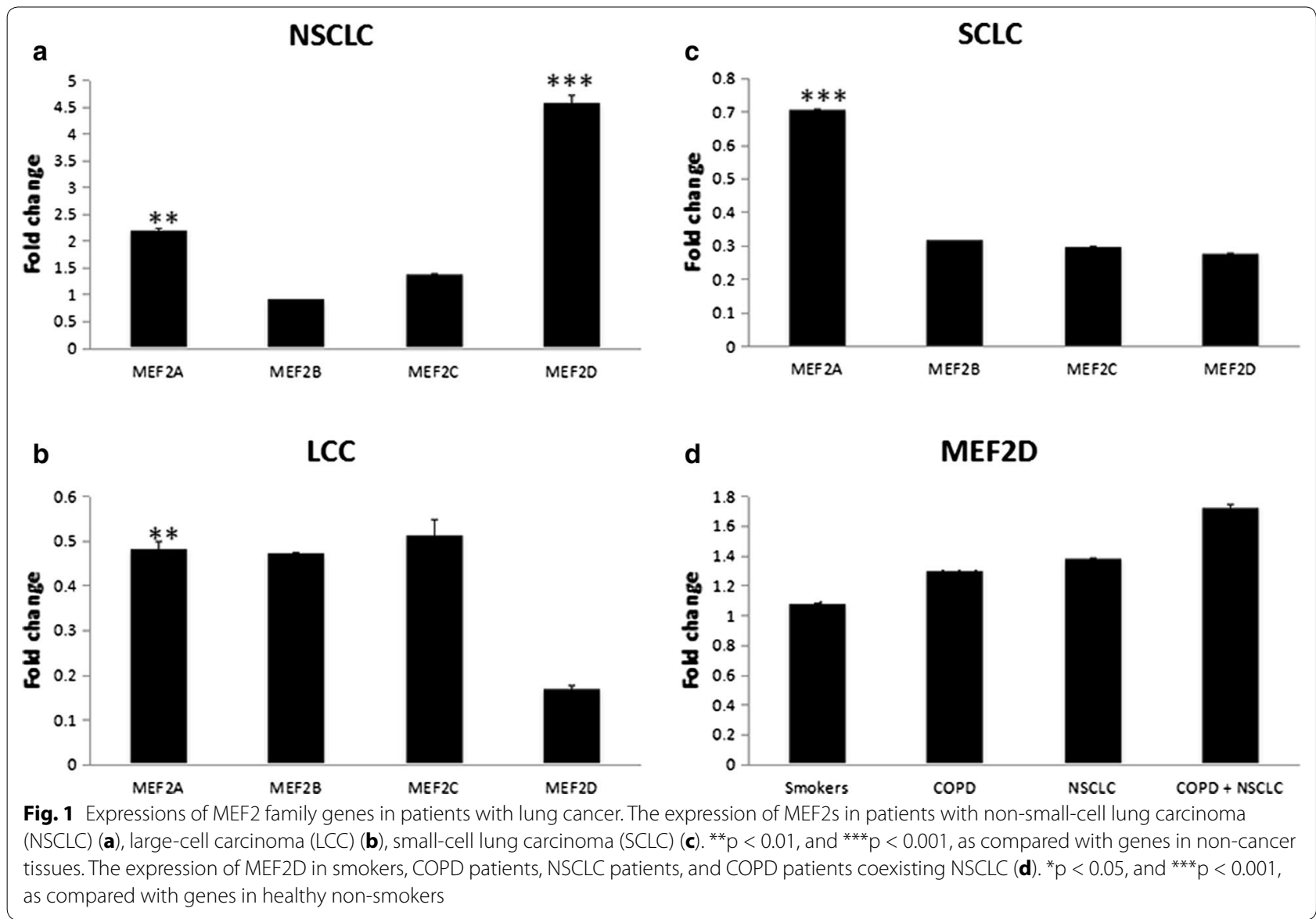

cells were stimulated with vehicles or LPS at $0.1,1 \mu \mathrm{g} /$ $\mathrm{ml}$ for $4 \mathrm{~h}$ or $8 \mathrm{~h}$, respectively. Figure 2a demonstrated the top ten genes up-expressed over twofold: HDAC4, HIST1H4J, EP300, HDAC5, CABIN1, GDF2, MEF2D, C1orf21, HIST1H2AK, and NKX2-8, as well as the top ten genes down-expressed over twofold: NR4A1, NFATC2, YWHAQ, CAMK4, FOS, KIAA1009, DKK3, NLRP13, MDK, and PRMT6, in LPS-stimulated A549 cells. Figure $2 \mathrm{~b}$ showed the gene network associated with MEF2D.

\section{MEF2D specifically up-regulated in inflammation-activated NSCLC cell line}

We investigated MEF2s gene expression in different lung cell lines through qRT-PCR analysis. We found that LPS challenge significantly up-regulated the mRNA levels of MEF2D in NSCLC cell line A549 cells, as compared with those stimulated with vehicle, in accordance with the RNA-seq results (Fig. 3a). The mRNA levels of MEF2D were also up-regulated in HBE cells after LPS stimulation, but the fold changes were lower than those in LPS-activated A549 cells (Fig. 3b). As shown in Fig. 3c, levels of MEF2D were not significantly altered in BEAS-2B cells.
MEF2D expressions increased associated with the severity of inflammation

The mRNA expressions of MEF2D in LPS-stimulated A549 cells increased in a concentration-dependent pattern and reached to the highest level when LPS concentration was $1 \mu \mathrm{g} / \mathrm{ml}$ (Fig. $4 \mathrm{a}, \mathrm{p}<0.001$ ). LPSstimulated expression of MEF2D mRNA increased in a time-dependent pattern as well, and reached to the highest level at $24 \mathrm{~h}$ after LPS stimulation (Fig. $4 \mathrm{~b}, \mathrm{p}<0.001$ ). The protein expressions of MEF2D also increased in a concentration- or time-dependent pattern after LPS stimulation, and reached to the highest level when LPS concentration was $1 \mu \mathrm{g} / \mathrm{ml}$ (Fig. $4 \mathrm{c}, \mathrm{p}<0.01$ ) or at $72 \mathrm{~h}$ after LPS stimulation (Fig. $4 \mathrm{~d}, \mathrm{p}<0.01$ ), respectively, in accordance with the mRNA expressions.

\section{MEF2D-deficiency impaired NSCLC cell bio-behaviors}

We used the real-time cell monitoring system to investigate the effect of MEF2D on cell bio-behaviors. We found that MEF2D-deficiency significantly reduced the capacity of cell proliferation (Fig. 5a), differentiation (Fig. 5b) or movement (Fig. 5c) in NSCLC cell line A549 cells, compared with the control cells. The role of MEF2D in A549 cells migration 


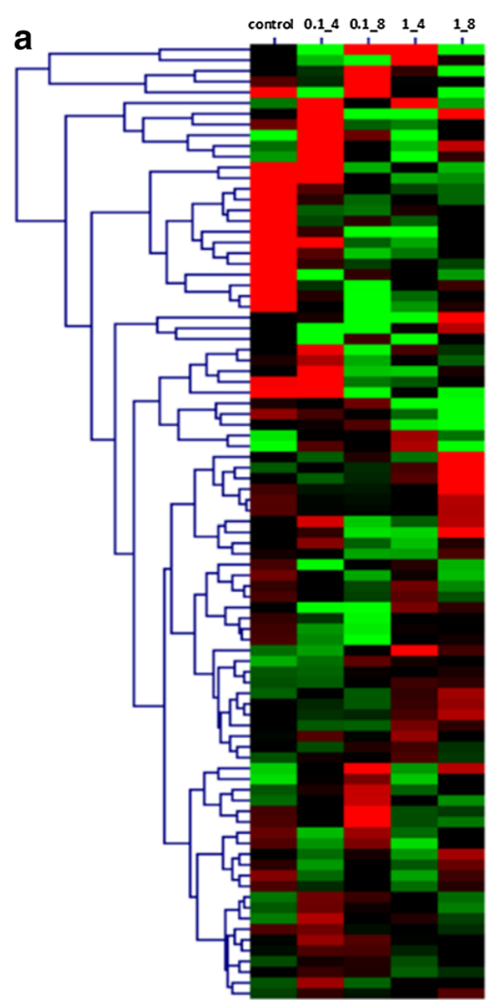

Up-regulated genes
\begin{tabular}{|l|l|}
\hline ID & Name \\
\hline 9759 & HDAC4 \\
\hline 8363 & HIST1H4J \\
\hline 2033 & EP300 \\
\hline 10014 & HDAC5 \\
\hline 23523 & CABIN1 \\
\hline 2658 & GDF2 \\
\hline 4209 & MEF2D \\
\hline 81563 & C1Orf21 \\
\hline 8330 & HIST1H2AK \\
\hline 26257 & NKX2-8 \\
\hline
\end{tabular}

Down-regulated genes
\begin{tabular}{|l|l|}
\hline ID & Name \\
\hline 3164 & NR4A1 \\
\hline 4773 & NFATC2 \\
\hline 10971 & YWHAQ \\
\hline 814 & CAMK4 \\
\hline 2353 & FOS \\
\hline 22832 & KIAA1009 \\
\hline 27122 & DKK3 \\
\hline 126204 & NLRP13 \\
\hline 4192 & MDK \\
\hline 55170 & PRMT6 \\
\hline
\end{tabular}

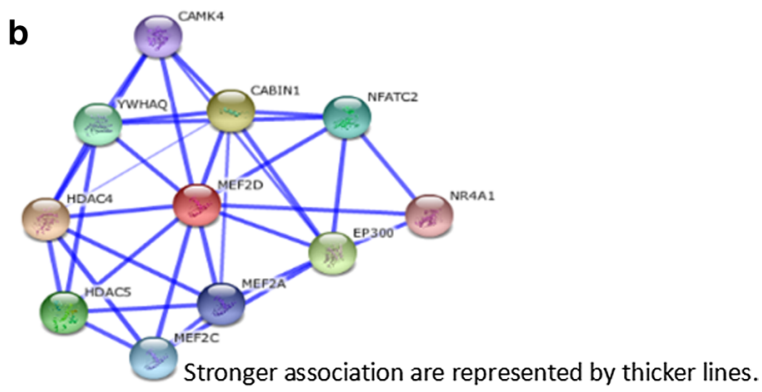

Fig. 2 Alterations of gene clusters in inflammation-activated NSCLC cell line. a The top ten genes expression more than twofold up- or downexpressed in LPS-stimulated A549 cells; b genes associated with MEF2D network

was further investigated by Transwell assay. As shown in Fig. 5d1, d2, MEF2D-knockdown A549 cells by siRNA had significantly impaired capacity of migration toward $10 \%$ FBS, compared with the control cells $(\mathrm{p}<0.01)$. The role of MEF2D in A549 cells proliferation was further investigated by CCK- 8 assay. As shown in Fig. 5e, capacity of cell proliferation was significantly reduced in MEF2D-knockdown A549 cells, compared with the control cells.

\section{Extracellular signal-regulated protein kinase (ERK) inhibition reversed up-regulation of MEF2D in inflammation-activated NSCLC cell line}

A549 cells respectively pretreated with ERK inhibitor PD98059 or PI3 K inhibitor LY290042 at doses of 10, 20 and $30 \mu \mathrm{M}$ for $2 \mathrm{~h}$ were then challenged with vehicle or LPS at the concentration of $1 \mu \mathrm{g} / \mathrm{ml}$ for $48 \mathrm{~h}$. Treatment with PD98509 significantly reversed LPS-induced upregulation of MEF2D (Fig. 6a, p < 0.05), while treatment with LY290042 did not alter the LPS-induced MEF2D expression significantly (Fig. 6b).

\section{Discussion}

MEF2D, a transcription factor of the MEF2 family, is not only critical for myogenesis, but also plays an important role in regulating diverse developmental programs [13]. It has been implicated that MEF2D is involved in different types of malignancies, including acute lymphoblastic leukemia, hepatocellular carcinoma and osteosarcoma [1418]. Recently, MEF2D has been reported to promote the growth of lung cancer [19]. In this study, we found that MEF2D was overexpressed in clinical NSCLC tissues. Further data mining showed significantly higher MEF2D level in COPD patients with NSCLC than that in smokers, patients with COPD and no NSCLC, or patients with NSCLC and no COPD. Growing evidence has shown that patients with chronic respiratory conditions such as COPD exhibit a significantly higher risk of lung cancer [8]. It is reported that $50-90 \%$ lung cancer patients have coexisting COPD [20]. Chronic inflammation associated with COPD seems to be a critical player in lung cancer development and prognosis [21, 22], related to $15-20 \%$ of cancer deaths [23], while little is known about the underlying mechanism. The results prompted us to further speculate whether MEF2D might act as a communicator between inflammation and lung cancer.

The present study adopted an in vitro model based on LPS-stimulated A549 to explore the underlying link between inflammation and lung cancer. Our data showed that MEF2D expression was significantly elevated in inflammation-activated NSCLC cell line A549 through 


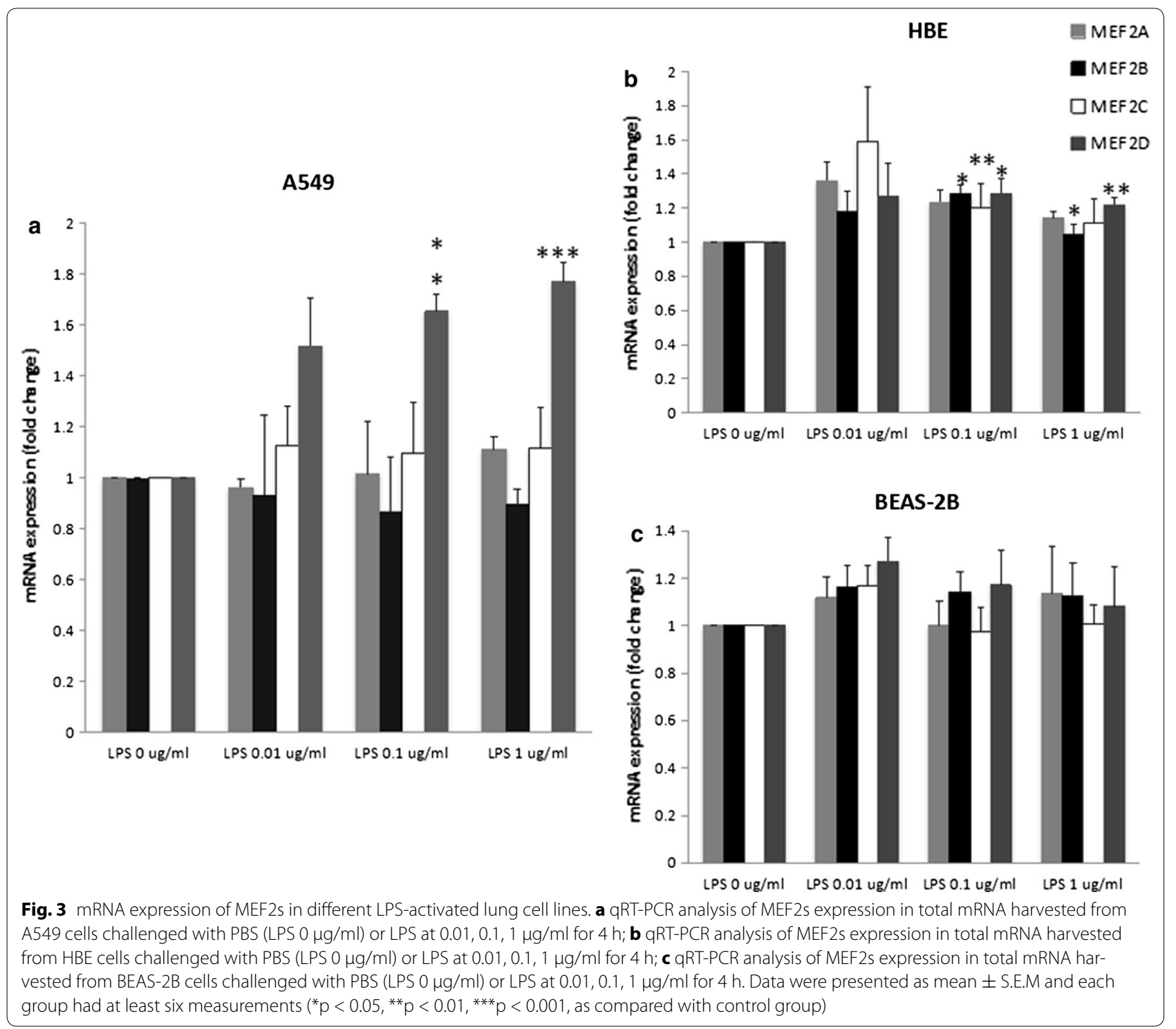

Ion Torrent-based RNA-sequencing analysis, as were genes associated with MEF2D network. LPS challenge specifically up-regulated the MEF2D mRNA expression in A549 significantly rather than in bronchial epithelial cell lines HBE or BEAS-2B cells. Our data also demonstrated that LPS challenge up-regulated the mRNA or protein levels of MEF2D in A549 in a LPS-concentration dependent and time dependent manner. It seems that the influencing roles of inflammation in the expression of MEF2D are related with the severities.

Diverse calcium-dependent signaling pathways have been revealed as regulators of MEF2 activity, including calcium/calmodulin-dependent protein kinase (CaMK) signaling, calcineurin signaling, and mitogen-activated protein kinase (MAPK) signaling [10]. MAPKs are mainly divided into three signaling cascades: ERK, p38 kinase and c-jun N-terminal kinase (JNK) pathways. In accordance with the previous study [24], we found that the ERK signaling pathway may play the critical and dependent role in the mechanism of MEF2D production of A549, evidenced by the finding that the over-production of MEF2D by LPS-challenge was prevented by ERK inhibitor. Further study is needed to demonstrate MEF2D targeted genes after inflammation challenge.

Inflammation plays multifaceted roles in all stages of tumorigenesis, including malignant transformation, tumor initiation to invasion, and metastasis of established tumor [25]. Cancer-related inflammatory microenvironment, mainly composed of inflammatory cells and mediators, has been accepted as a significant factor through which inflammation contributes to the multiple capabilities of cancer [26]. Our previous study reported 

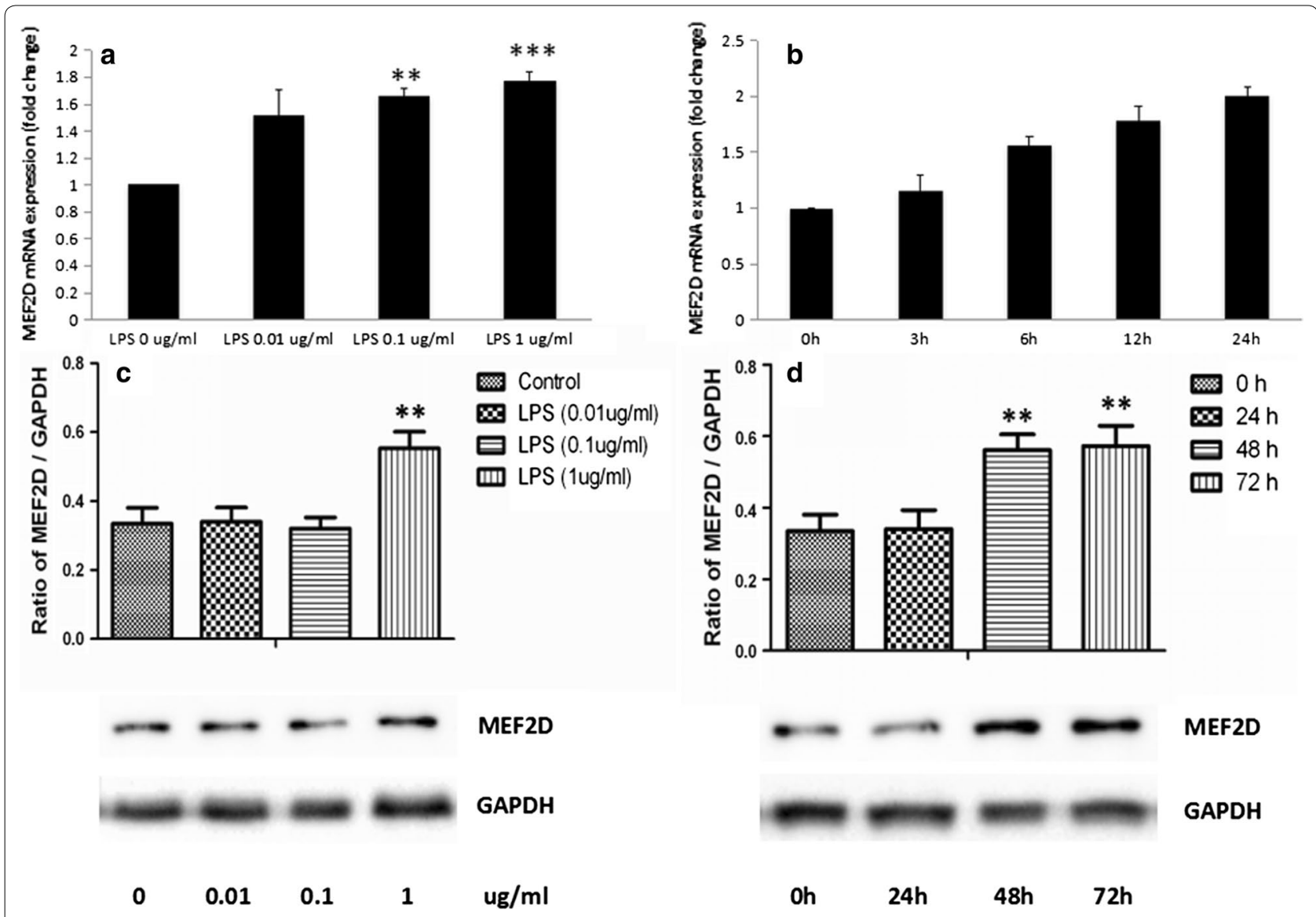

\section{$\begin{array}{lllll}0 & 0.01 & 0.1 & 1 & \mathrm{ug} / \mathrm{ml}\end{array}$}

Oh $\quad 24 \mathrm{~h}$

Fig. 4 Expressions of MEF2D in LPS-activated NSCLC cell line. a qRT-PCR analysis of MEF2D mRNA expression in total mRNA harvested from A549 cells challenged with PBS (LPS $0 \mu \mathrm{g} / \mathrm{ml}$ ) or LPS at $0.01,0.1,1 \mu \mathrm{g} / \mathrm{ml}$ for $4 \mathrm{~h} ; \mathbf{b}$ qRT-PCR analysis of MEF2D mRNA expression in total mRNA harvested from A549 cells challenged with LPS at $1 \mu \mathrm{g} / \mathrm{ml}$ from 0 to $24 \mathrm{~h}$; $\mathbf{c}$ Western blotting analysis of MEF2D protein expression in A549 cells challenged with PBS (LPS $0 \mu \mathrm{g} / \mathrm{ml}$ ) or LPS at 0.01, $0.1,1 \mu \mathrm{g} / \mathrm{ml}$ for $48 \mathrm{~h}$; d Western blotting analysis of MEF2D protein expression in A549 cells challenged with LPS at $1 \mu \mathrm{g} / \mathrm{ml}$ from 0 to $72 \mathrm{~h}$. Data were presented as mean \pm S.E.M and each group had at least six measurements $\left({ }^{* *} p<0.01,{ }^{* * *} p<0.001\right.$, as compared with control group)

that inflammation-activated lung cells could act as the initiators and/or secondary sources of the development of cancer microenvironment [27]. Consistent with our previous study, we provide further evidence that inflammatory conditions might contribute to remodeling of the cancer microenvironment through up-regulating MEF2D expression.

During a host response to bacterial pathogens, activation of MEF2 by p38 kinase pathway has been related to expression of pro-inflammatory cytokines [28]. In primary human $T$ lymphocytes, MEF2D is required for the synthesis of IL-2 mRNA and secretion of IL-2 in response to $\mathrm{T}$ cell receptor stimulation [29]. MEF2 participates in the regulation of $B$ lymphocyte proliferation and survival after B cell receptor stimulation [30]. MEF2D is identified as an important regulator of IL-10 gene expression [31]. Given the critical roles of MEF2 in regulation of inflammatory responses, up-regulation of MEF2D might lead to remodeling of cancer microenvironment through lymphocytes recruitment or mediators production during inflammatory condition. Further in vitro study is needed to clarify the underlying mechanism.

MEF2D has been reported to serve as oncogene in B cell acute lymphoblastic leukemia [15] and hepatocellular carcinoma [16, 32-34] through promotion of colony formation and proliferation, inhibition of apoptosis, epithelial-mesenchymal transition and invasiveness. MEF2D also acts as tumor suppressor in liposarcoma, leiomyosarcoma [35] and rhabdomyosarcoma [36, 37] through promotion of cell proliferation and anchorage independent growth and inhibition of differentiation. Consistent with the previous studies, we found that MEF2D played a critical role in bio-behaviors of NSCLC cells. While targeted knockdown of MEF2D gene via siRNA significantly impaired the capacity of cancer cell differentiation, proliferation or movement. Up-regulation of MEF2D during 


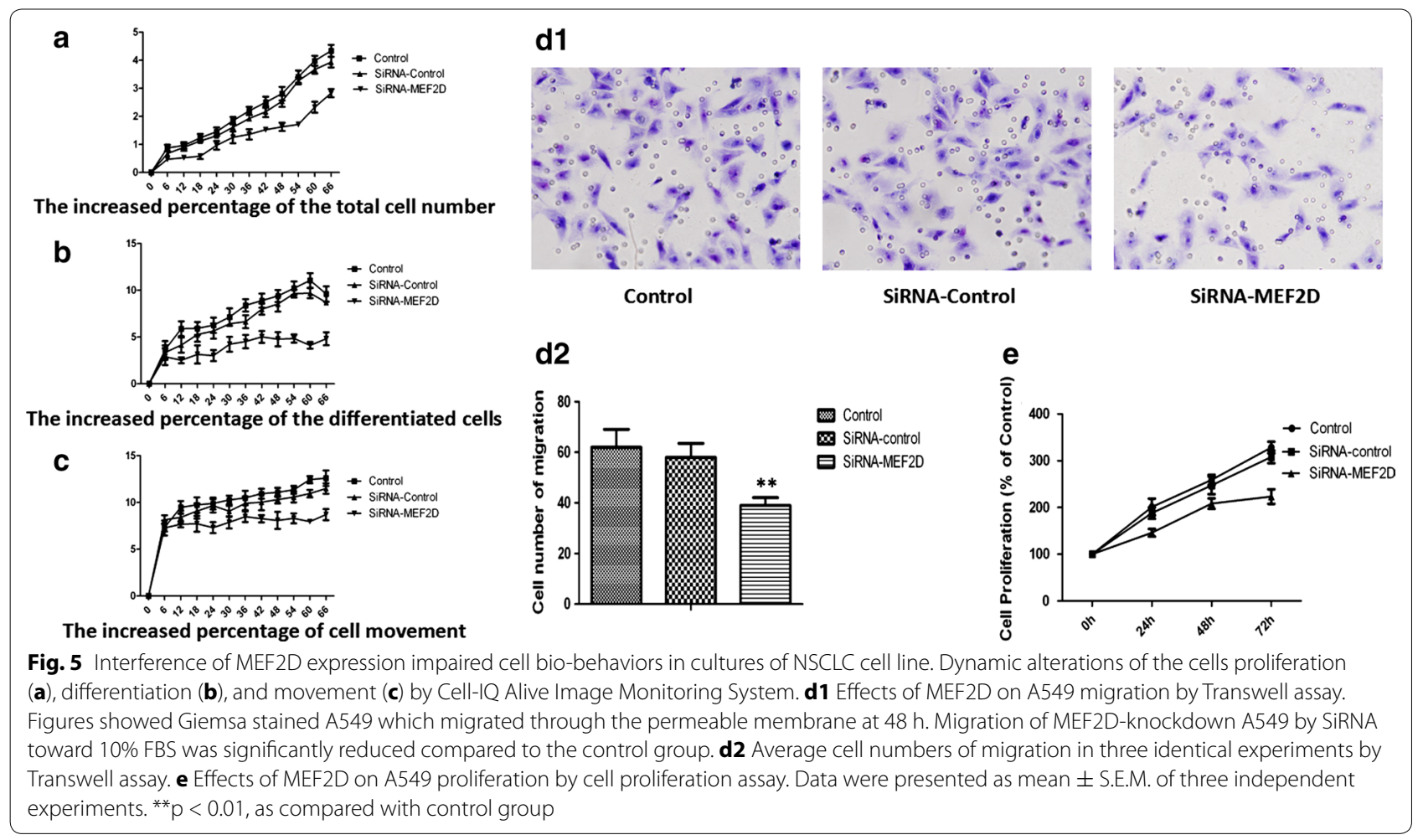

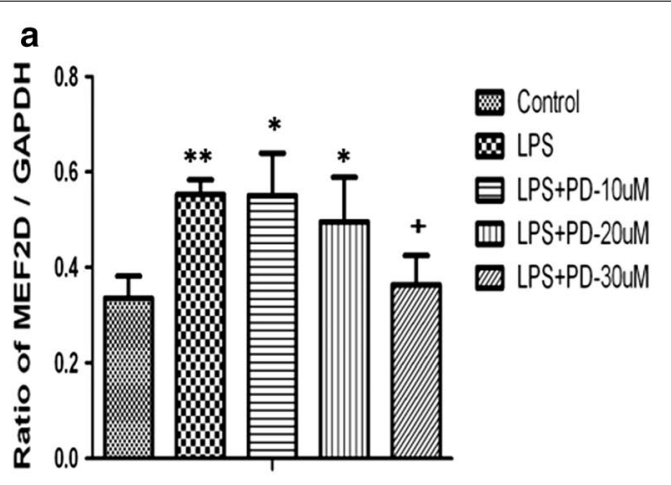

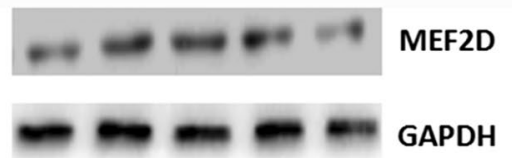

b

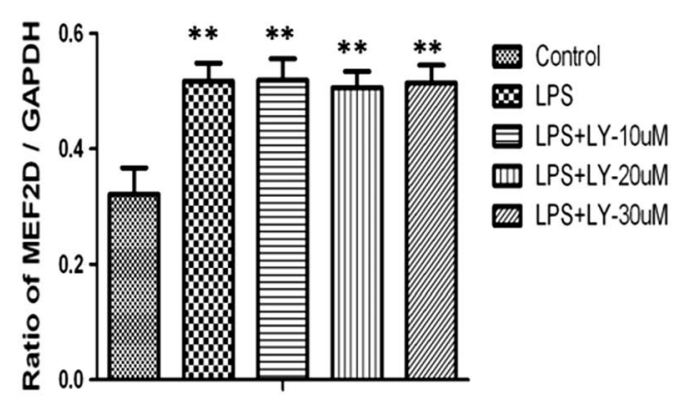

MEF2D

GAPDH

Fig. 6 Effects of signaling pathway inhibitors on LPS-induced MEF2D expression. a Western blotting analysis of MEF2D protein expression in A549 cells pretreated with ERK inhibitor PD98059 at doses of 10, 20 and $30 \mu \mathrm{M}$ for $2 \mathrm{~h}$ and then stimulated with LPS (1 $\mu \mathrm{g} / \mathrm{ml}$ ) for 48 h; b Western blotting analysis of MEF2D protein expression in A549 cells pretreated with PI3K inhibitor LY290042 at doses of 10, 20 and $30 \mu \mathrm{M}$ for $2 \mathrm{~h}$ and then stimulated with LPS $(1 \mu \mathrm{g} / \mathrm{ml})$ for $48 \mathrm{~h}$. Data were presented as mean \pm S.E.M and each group had at least six measurements. ${ }^{*} \mathrm{p}<0.05$, ${ }^{* *} \mathrm{p}<0.01$, as compared with control group. ${ }^{+} p<0.05$, as compared with LPS group

inflammatory condition might favor lung cancer cell differentiation, proliferation, or movement.

Briefly, inflammatory conditions led to increased MEF2D expression, which might further contribute to the development of malignancy through influencing cancer microenvironment and cell bio-behaviors. As far as we know, this is the first study focused on MEF2D as a "communicator" between chronic inflammation and 
lung cancer. MEF2D might be a potential biomarker for patients with chronic respiratory diseases, such as COPD, who are at risk of developing lung cancer.

However, the present study has some limits. Although we adopted an in vitro model based on LPS-stimulated A549 to mimic inflammatory conditions of airways, there are still differences between chronic airway inflammation in vivo and the in vitro model. Much more remains to be learned about the regulatory mechanism of MEF2D to communicate between chronic inflammation and lung cancer.

\section{Conclusions}

Taken together, the present study demonstrated significantly higher MEF2D level in COPD patients with NSCLC than that in smokers, patients with COPD and no NSCLC, or patients with NSCLC and no COPD. Inflammation challenge increased MEF2D expression in A549, associated with the severity of inflammation, while ERK inhibition could reverse the up-regulation of MEF2D. MEF2D played a critical role in NSCLC cell differentiation, proliferation, or movement. MEF2D might contribute to the development of lung cancer through influencing cancer microenvironment and cell bio-behaviors during inflammatory conditions. MEF2D provides a cross-talk between chronic inflammation and lung caner. MEF2D could be a potential biomarker predicting risk of lung cancer among patient with chronic respiratory diseases. More studies are still needed to explore the further mechanism between chronic inflammation and lung cancer.

\section{Additional file}

Additional file 1: Table S1. Sequences of siRNA targeting MEF2D.

\begin{abstract}
Abbreviations
COPD: chronic obstructive pulmonary disease; qRT-PCR: quantitative real time polymerase chain reaction; GEO: Gene Expression Omnibus; MEF2D: myocyte enhancer factor 2D; NSCLC: non-small-cell lung carcinoma; LCC: large-cell carcinoma; SCLC: small-cell lung carcinoma; MEF2: myocyte enhancer factor 2; ERK: extracellular signal-regulated protein kinase; siRNA: small interfering RNA; CaMK: calcium/calmodulin-dependent protein kinase; MAPK: mitogenactivated protein kinase; JNK: c-jun N-terminal kinase.
\end{abstract}

\section{Authors' contributions}

$\mathrm{HZ}$ and LS contributed to the laboratory work. Yong Zhang contributed to the bioinformatics analyses. Yi-chun Zhu contributed to the statistical analyses. CB and XW contributed to the study design. JZ contributed to the study design, laboratory work, and grant application. All authors read and approved the final manuscript.

\footnotetext{
Author details

${ }^{1}$ Department of Pulmonary Medicine, Ruijin Hospital, Shanghai Jiaotong University School of Medicine, Shanghai, China. ${ }^{2}$ Department of Pulmonary Medicine, Zhongshan Hospital, Fudan University, 180 Fenglin Road, Shanghai 200032, China. ${ }^{3}$ Shanghai Respiratory Research Institute, Shanghai, China. ${ }^{4}$ Institute of Clinical Science, Zhongshan Hospital, Fudan University, Shanghai, China. ${ }^{5}$ Fudan University Center for Clinical Bioinformatics, Shanghai, China.
}

\section{Acknowledgements}

We are grateful for the collaboration of Zhongshan Hospital, Fudan University, and their stuff.

\section{Competing interests}

The authors declare that they have no competing interests.

\section{Availability of data and materials}

The datasets analyzed during the current study are available in the Gene Expression Omnibus (GEO) online database.

\section{Funding}

This work was supported by the National Natural Science Foundation of China (Grant Numbers 81500025, 81600014, 81600027).

Received: 16 February 2017 Accepted: 19 March 2017

Published online: 24 March 2017

\section{References}

1. Jemal A, Bray F, Center MM, Ferlay J, Ward E, Forman D. Global cancer statistics. CA Cancer J Clin. 2011;61:69-90.

2. Barreiro E, Fermoselle C, Mateu-Jimenez M, Sánchez-Font A, Pijuan L, Gea J, et al. Oxidative stress and inflammation in the normal airways and blood of patients with lung cancer and COPD. Free Radic Biol Med. 2013;65:859-71.

3. Mateu-Jiménez M, Sánchez-Font A, Rodríguez-Fuster A, Aguilo R, Pijuan $L$, Fermoselle $C$, et al. Redox imbalance in lung cancer of patients with underlying chronic respiratory conditions. Mol Med. 2016. doi:10.2119/ molmed.2015.00199.

4. Barnawi J, Tran HB, Roscioli E, Hodge G, Jersmann H, Haberberger R, et al. Pro-phagocytic effects of thymoquinone on cigarette smoke-exposed macrophages occur by modulation of the sphingosine-1-phosphate signalling system. COPD. 2016;13(5):653-61.

5. Bernardo I, Bozinovski S, Vlahos R. Targeting oxidant-dependent mechanisms for the treatment of COPD and its comorbidities. Pharmacol Ther. 2015;155:60-79.

6. Kuźnar-Kamińska B, Mikuła-Pietrasik J, Sosińska P, Ksiqźek K, BaturaGabyyel H. COPD promotes migration of A549 lung cancer cells: the role of chemokine CCL21. Int J Chron Obstruct Pulmon Dis. 2016;11:1061-6.

7. Sohal SS, Mahmood MQ, Walters EH. Clinical significance of epithelial mesenchymal transition (EMT) in chronic obstructive pulmonary disease (COPD): potential target for prevention of airway fibrosis and lung cancer. Clin Transl Med. 2014;3(1):33.

8. Wang X. New biomarkers and therapeutics can be discovered during COPD-lung cancer transition. Cell Biol Toxicol. 2016;32(5):359-61.

9. Barreiro E, Bustamante V, Curull V, Gea J, Lopez-Campos JL, Munoz X. Relationships between chronic obstructive pulmonary disease and lung cancer: biological insights. J Thorac Dis. 2016;8(10):E1122-35.

10. McKinsey TA, Zhang CL, Olson EN. MEF2: a calcium-dependent regulator of cell division, differentiation and death. Trends Biochem Sci. 2002;27(1):40-7.

11. Natanek SA, Gosker HR, Slot IG, Marsh GS, Hopkinson NS, Moxham J, et al. Pathways associated with reduced quadriceps oxidative fibers and endurance in COPD. Eur Respir J. 2013;41(6):1275-83.

12. Pon JR, Marra MA. MEF2 transcription factors: developmental regulators and emerging cancer genes. Oncotarget. 2016;7(3):2297-312.

13. Potthoff MJ, Olson EN. MEF2: a central regulator of diverse developmental programs. Development. 2007;134(23):4131-40.

14. Prima V, Gore L, Caires A, Boomer T, Yoshinari M, Imaizumi M, et al. Cloning and functional characterization of MEF2D/DAZAP1 and DAZAP1/ MEF2D fusion proteins created by a variant $t(1 ; 19)(q 23 ; p 13.3)$ in acute lymphoblastic leukemia. Leukemia. 2005;19(5):806-13.

15. Prima V, Hunger SP. Cooperative transformation by MEF2D/DAZAP1 and DAZAP1/MEF2D fusion proteins generated by the variant $t(1 ; 19)$ in acute lymphoblastic leukemia. Leukemia. 2007;21(12):2470-5.

16. Ma L, Liu J, Liu L, Duan G, Wang Q, Xu Y, et al. Overexpression of the transcription factor MEF2D in hepatocellular carcinoma sustains malignant character by suppressing G2-M transition genes. Cancer Res. 2014;74(5):1452-62. 
17. Zhao X, Liu M, Li D. Oleanolic acid suppresses the proliferation of lung carcinoma cells by miR-122/Cyclin G1/MEF2D axis. Mol Cell Biochem. 2015;400(1-2):1-7.

18. Yu H, Sun H, Bai Y, Han J, Liu G, Liu Y, et al. MEF2D overexpression contributes to the progression of osteosarcoma. Gene. 2015;563(2):130-5.

19. Song L, Li D, Zhao Y, Gu Y, Zhao D, Li X, et al. miR-218 suppressed the growth of lung carcinoma by reducing MEF2D expression. Tumor Biol. 2016;37(3):2891-900.

20. Zhang J, Zhou JB, Lin XF, Wang Q, Bai CX, Hong QY. Prevalence of undiagnosed and undertreated chronic obstructive pulmonary disease in lung cancer population. Respirology. 2013;18(2):297-302.

21. Turner MC, Chen Y, Krewski D, Calle EE, Thun MJ. Chronic obstructive pulmonary disease is associated with lung cancer mortality in a prospective study of never smokers. Am J Respir Crit Care Med. 2007;176(3):285-90.

22. Ueda K, Jinbo M, Li TS, Yagi T, Suga K, Hamano K. Computed tomographydiagnosed emphysema, not airway obstruction, is associated with the prognostic outcome of early-stage lung cancer. Clin Cancer Res. 2006;12(22):6730-6.

23. Kuper $\mathrm{H}$, Adami HO, Trichopoulos D. Infections as a major preventable cause of human cancer. J Intern Med. 2000;248(3):171-83.

24. Marinissen MJ, Chiariello M, Pallante M, Gutkind JS. A network of mitogen-activated protein kinase links $\mathrm{G}$ protein-coupled receptors to the c-jun promoter: a role for c-Jun NH2-terminal kinase, p38s, and extracellular signal-regulated kinase 5. Mol Cell Biol. 1999;19(6):4289-301.

25. Conway EM, Pikor LA, Kung SH, Hamilton MJ, Lam S, Lam WL, et al. Macrophages, inflammation, and lung cancer. Am J Respir Crit Care Med. 2016;193(2):116-30.

26. Shi L, Wang L, Hou J, Zhu B, Min Z, Zhang M, et al. Targeting roles of inflammatory microenvironment in lung cancer and metastasis. Cancer Metastasis Rev. 2015;34(2):319-31.

27. Zhou J, Min Z, Zhang D, Wang W, Marincola F, Wang X. Enhanced frequency and potential mechanism of B regulatory cells in patients with lung cancer. J Transl Med. 2014;12:304.

28. Han J, Jiang Y, Li Z, Kravchenko W, Ulevitch RJ. Activation of the transcription factor MEF2C by the MAP kinase p 38 in flammation. Nature. 1997;386(6622):296-9.
29. Pan F, Ye Z, Cheng L, Liu JO. Myocyte enhancer factor 2 mediates calcium-dependent transcription of the interleukin-2 gene in $T$ lymphocytes: a calcium signaling module that is distinct from but collaborates with the nuclear factor of activated T cells (NFAT). J Biol Chem. 2004;279(15):14477-80.

30. Wilker PR, Kohyama M, Sandau MM, Albring JC, Nakagawa O, Schwarz JJ, et al. Transcription factor Mef2c is required for B cell proliferation and survival after antigen receptor stimulation. Nat Immunol. 2008;9(6):603-12.

31. Yang S, Gao L, Lu F, Wang B, Gao F, Zhu G, et al. Transcription factor myocyte factor 2D regulated interleukin-10 production in microglia to protect neuronal cells from inflammation-induced death. J Neuroinflammation. 2015;12:33.

32. Yu W, Huang $C$, Wang $Q$, Huang $T$, Ding $Y, M a C$, et al. MEF2 transcription factors promotes EMT and invasiveness of hepatocellular carcinoma through TGF- $\beta 1$ autoregulation circuitry. Tumour Biol. 2014;35(11):10943-51.

33. Bai X, Wu L, Liang T, Liu Z, Li J, Li D, et al. Overexpression of myocyte enhancer factor 2 and histone hyperacetylation in hepatocellular carcinoma. J Cancer Res Clin Oncol. 2008;134(1):83-91.

34. Bai XL, Zhang Q, Ye LY, Liang F, Sun X, Chen Y, et al. Myocyte enhancer factor $2 \mathrm{C}$ regulation of hepatocellular carcinoma via vascular endothelial growth factor and Wnt/ß-catenin signaling. Oncogene. 2015;34(31):4089-97.

35. Di Giorgio E, Clocchiatti A, Piccinin S, Sgorbissa A, Viviani G, Peruzzo P, et al. MEF2 is a converging hub for histone deacetylase 4 and phosphatidylinositol 3-kinase/Akt-induced transformation. Mol Cell Biol. 2013;33(22):4473-91.

36. Zhang M, Zhu B, Davie J. Alternative splicing of MEF2C controls its activity in normal myogenesis and promotes tumorigenicity in rhabdomyosarcoma cells. J Biol Chem. 2015;290(1):310-24.

37. Zhang M, Truscott J, Davie J. Loss of MEF2D expression inhibits differentiation and contributes to oncogenesis in rhabdomyosarcoma cells. Mol Cancer. 2013;12(1):150.

\section{Submit your next manuscript to BioMed Central and we will help you at every step:}

- We accept pre-submission inquiries

- Our selector tool helps you to find the most relevant journal

- We provide round the clock customer support

- Convenient online submission

- Thorough peer review

- Inclusion in PubMed and all major indexing services

- Maximum visibility for your research

Submit your manuscript at www.biomedcentral.com/submit
() Biomed Central 